\title{
The Traits of the Innovator: Five-Factor Model Analysis and Exemplification
}

\author{
Filippo Vannella* \\ KTH Royal Institute of Technology, Stockholm, Sweden \\ Email:vannella@kth.se
}

\begin{abstract}
Within the business context, the study of the innovator's personal traits is a fundamental analysis to be carried out in order to understand in a complete way how the innovation process takes place and find out which traits are necessary to make it happen. Based on the five-factor model, this work explores how personality traits are related to successful ways to innovate and provides a contemporary example analysis by studying one of the nowadays most innovative personalities: Elon Musk. By comparing the five-factor model with this concrete experimental case, conclusions will be drawn on the effectiveness of the model by proposing a possible interpretation of the five-factors model from a practical perspective.
\end{abstract}

Keywords: Innovation; five-factor model; personality traits; innovation analysis.

\section{Introduction}

In a very broad sense, the concept of innovation refers to the process of developing and implementing a new idea [1]. This definition suggests that two main steps are necessary in order to make this complex process possible: coming up with a novel idea and bringing it to fruition. The first is related to creativity, which is the production of novel and useful ideas in any domain. In contrast, the second characterizes the usability in terms of the successful implementation of the creative idea [2]. The figure of the innovator merges these two essential factors. Research has shown that innovator individuals exhibit recurrent and peculiar psychological traits and behaviors [3]. This paper aims to delineate the identity of the innovator by highlighting the main traits that characterize an innovative personality.

\section{The Five-Factor Model}

In order to carry out the investigation on the innovator's traits, it is necessary to establish a framework to describe the personality of an individual adequately. One of the most widely adopted models is the Five-Factor Model (FFM) of personality [4]. Such a model allows organizing a vast variety of personality variables into a set of constructs to search for consistent and meaningful relationships [3] between these constructs. In other words, the FFM is a hierarchical organization of personality traits in terms of five basic characters determining the personality of an individual: extraversion, agreeableness, conscientiousness, neuroticism, and openness to experiences, (see Fig. 1).

By using these fundamental characters, it is possible to analyze the innovator's personality in a structured and precise way. The analysis methodology followed in this paper consists in establishing a set of hypotheses on the correlation between the five personality factors and the attitude towards an innovative behavior. This methodology will highlight the most important factors to foster innovation.

* This work was developed while the author was part of Alta Scuola Politecnica (ASP), a Double Degree Programme between Polytechnic University of Turin and Polytechnic University of Milan. 


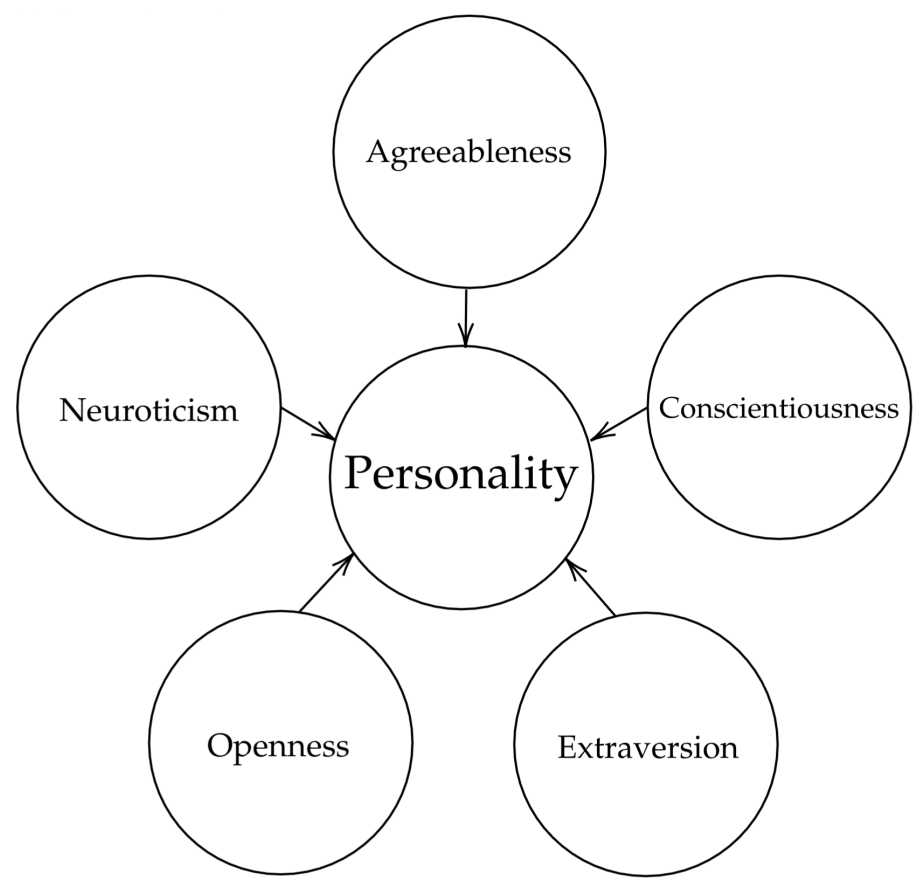

Figure 1: Depiction of the Five-Factor model.

Neuroticism is the trait related to emotional stability and reactivity to stress. Individuals high on neuroticism tend to experience several of negative emotions, including anxiety, hostility, depression, impulsiveness, and vulnerability [5]. On the opposite, people with low neuroticism are emotionally stable, calm, self-sufficient, and can manage the stressful situations without getting agitated. Patterson also relates persistence and tolerance to emotional stability [6]. Innovation implies swift changes that could lead to stress and anxiety [5]. This implies the innovator's personality to be emotionally stable. Hypothesis 1: Innovation is negatively related to neuroticism.

Extraversion is the dimension related to sociability and describes the extent to which people are assertive, energetic, talkative, active, and enthusiastic [5]. On the contrary, introverted individuals are reserved, shy, and less involved in the social world. It turns out that the innovator's personality must be highly extroverted. This is mainly because the innovator must be engaging and energic in promoting his ideas and making others believe in his projects. Hypothesis 2: Innovation is positively related to extraversion.

Openness to experiences is the trait that characterizes an individual that is intellectual, curious, imaginative, cultured, broad-minded [7]. This characteristic depends on the individual's intelligence, especially aspects of intelligence related to creativity, such as divergent thinking [8]. King et al. pointed out that, within the five factors, openness to experiences is one of the most related to creativity, which is a crucial element for innovation [9]. It is important to note that creativity is necessary, but not sufficient condition to make innovation happen. Hypothesis 3: Innovation is positively related to openness to experiences.

Agreeableness is the factor that determines how an individual is good-natured, altruistic, trusting, and tolerant towards others. Also, agreeable people are keen to cooperate and help other people, and easy to get on with. Instead, a disagreeable individual can be characterized as manipulative, ruthless, easily vexed, and self-centered [5]. Researches have shown that agreeableness has a very negative dependence on innovation. This is because individuals with a low degree of agreeableness tend to compete rather than cooperate [5], and they are less conformant and independent: two essential peculiarities of an innovative personality [9]. Hypothesis 4: Innovation is negatively related to agreeableness. 
Conscientiousness is the propensity to be self-responsible, organized, persistent, and motivated to pursue the goal accomplishment. It can also be seen as an indicator of volition, persistence, and hard-working [10]. Usually, high scores on conscientiousness indicate a preference for planned rather than spontaneous behavior [5]. Discording opinions on whether conscientiousness is a positive or negative attribute for an innovator are found in the literature. According to Mount et al., self-discipline and hard work can improve creative productivity [11], while other authors [12,6] stated that high conscientiousness might lead to resistance to change, which in turn have adverse effects on creativity. In the following, we assume a positive relation, although we point out that apparently there is no agreed position on this point. Hypothesis 5 : Innovation is positively related to conscientiousness.

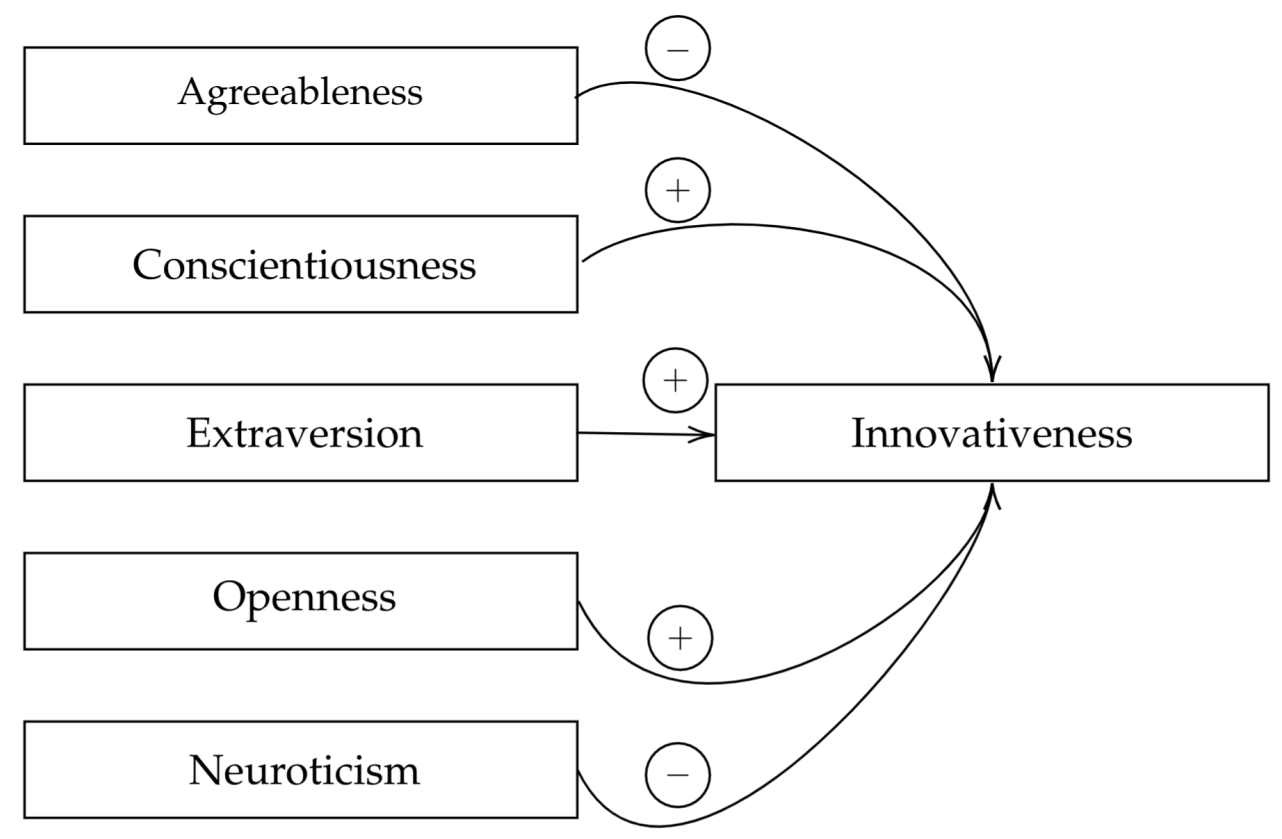

Figure 2: Schematic representation of the qualitative correlation between the five-factors and an innovative behaviour.

\section{Elon Musk: an Eclectic Innovator}

Elon Reeve Musk is regarded as being one of the most innovative and visionary personalities in the contemporary scenario. Born in South Africa in 1971, the young Elon showed peculiar characters that foreshadowed his bright career since his early childhood. Besides being a voracious reader, he learned at an incredible speed and he exhibited already a basic entrepreneurial thinking. At the age of twelve, he taught himself computer programming and figured out how to sold a videogame code to a computer magazine [13]. After earning two bachelor's degrees in economics and physics, he dropped out of his Ph.D. at Stanford University to join his entrepreneurial venture. As he affirmed later: "when I was in college, I wanted to be involved in things that would change the world. Now I am" [14]. In fact, from that point on, he became a serial entrepreneur, collecting concatenation of astonishing successes that have been revolutionizing many fields, including internet services, space and automotive industry, renewable energy, artificial intelligence, and many others. A chronological analysis of Musk's case is provided by considering his major and innovative enterprises. 


\subsection{The Internet venture}

During the 90s, while the internet was booming, Musk established his first two companies, known as Zip2 (1995) and PayPal (1999). The core service of Zip2 was providing online city guide software to newspapers' websites [15] while Paypal is a worldwide popular online payment system. These two companies brought significant renovations in the internet services and acted as a springboard for the newcomer's career, which showed since from his very first experience a real spirit of innovation and enterprise. The turning point came when Compaq Computer and eBay purchased Zip2 and Paypal for 307 million dollars and 1.5 billion dollars respectively [10]. These funds allowed him to pursue higher valuable goals and more creative challenges.

\subsection{Mars rockets, electric cars, and solar power}

Despite being one of the youngest millionaires worldwide after the sale of Paypal, the tireless entrepreneur embarked on other ambitious and visionary projects. With SpaceX (2002) he envisioned the possibility to reduce space transportation costs with the goal to provide reusable rockets and ultimately to "make humans a multi-planetary species".

Never resting on his laurels in 2004 Musk joined Tesla, a company aimed at producing mass-market fully electric cars and revolutionizing the automotive sector. As complementary assets to Tesla, Solar City (2006) powered through solar panel mounted on houses roof (solar roof) Tesla batteries for both Tesla car and every appliance in the house. It is worth highlighting the strong Musk's inclination to take risks that emerges from these business cases; as he affirmed: "My proceeds from PayPal were \$180M. I put \$100M in SpaceX, \$70M in Tesla, and \$10M in SolarCity. I had to borrow money for rent" [16].

\subsection{Hyperloop and AI}

Musk's last activities moved towards high-speed transport systems with Hyperloop (2012) and two companies operating in the artificial intelligence field: Open AI (2015) and Neuralink (2016). Hyperloop proposes a new paradigm using reduced-pressure tubes to achieve a speed higher than airliner speed. While the AI companies were born to develop artificial intelligence in a safe and beneficial way as Musk is strongly convinced that AI represents one of the biggest humanity's existential threats [17] and must be counteracted in some way. Also, these case studies confirm Musk's incredible versatility and his capability to explore different fields, shaping the world with his innovative ideas and technologies.

\section{Discussion}

The powerful innovative force of Elon Musk makes him a case of particular interest to study. By using the FFM, the personality traits of this contemporary innovator are analyzed on the basis of his successful career and the behavior he has exhibited in different situations.

One of the Musk's strongest suit is the high emotional stability (low neuroticism) he is able to maintain in difficult and stressful circumstances. As stated by one of his collaborators, in times of crisis "Elon gets hyperrational [...] The harder it gets, the better he gets" [13]. He has continuously taken huge business risks by investing all his assets in innovative ventures, and he managed to solve all the crises he faced in a masterful way. Moreover, his incredible resilience makes him stronger after every wrong attempt. One of his most famous quotes affirm:"Failure is an option here. If things are not failing, you are not innovating enough" [18]. 
Musk always demonstrated an innate curiosity for knowledge and turned out to be an exceptional autodidact and thinker. He trained himself to a particular way of thinking consisting in "Boil things down to the most fundamental truths. Then reason up from there" [19]. His extraordinary open-mindness allow him to seek very different innovations that are rapidly re-shaping human existence as we know it. Behind every Musk's innovation, there is the visionary desire to make the world a better place as it is summarized in his thought: "We need to figure out how to have the things we love, and not destroy the world" [20].

When it comes to investigating about Musk's way to relations with colleagues and employees, there have been many episodes reported that point out his harsh nature in cases of contrasts with others. According to Matus, he often lashes out at employees if they are not following his guidelines or if they fail to live up to his expectations [21]. Also, The Journal reported that "some high-level managers quit or were fired after clashing with the chief executive over Mr. Musk's insistence on doing things his way" [22].

At first glance, Musk could look like a very extroverted leader: he looks not afraid of public platforms, and he can be seen on stages making unveils of new products, charity speaking, connecting with customers, or asking for reviews and opinions. This impression could be misleading on his real nature: he declared that he is "basically like an introverted engineer, so, it took a lot of practice and effort to be able to go up on stage and not just stammer basically"[23]. Nonetheless, he is able to transmit his profound motivations to the people that work with him and to push them up to their limit to achieve the best results possible.

For what concerns conscientiousness, Mr. Musk exhibits an extremely strong attitude to efficiency, hard-working, and organization. During an interview, he affirmed to work between 80 hours and 100 hours a week and he tends to be very organized and precise in everything he does [24]. One of his closest collaborators affirmed: "He has the ability to work harder and endure more stress than anyone I have ever met" [13]. He always has alternatives in case of failures, as for the four failed launches in SpaceX, and his remarkable resiliency allows him to recover quickly from failures. As proved by the success of his companies, Musk is able to manage many businesses at the same time, staying focused on the main objectives, and he has a strong cogency that allows him to make the people believe in projects that could seem impossible to others.

\section{Conclusion}

In this paper, we analyzed the traits of the innovator through the lens of the FFM. We first presented the fundamentals concept of the FFM, and we established a set of hypotheses on the correlations between the five factors and an individual's innovativeness. We apply the FFM and it's correlation assumption on the study of the personality of one of the century's most innovative personalities: Elon Musk. We discuss the assumptions and proceed to validate or discard the hypotheses for this important exemplification, based on the chronological history of achievements and the analysis of the Musk's personality. This analysis shed a new light on the relations between personal traits of an individual and it's capacity to foster innovation into the world. Future work include further validation and refinition of the hypotheses, based on the study and analysis of innovative personalities. 


\section{Bibliografy}

[1] A.H. Van de Ven - H.L. Angle - M.S. Poole Research on the Management of Innovation: The Minnesota Studies, Oxford University Press (2000).

[2] T.M. Amabile Creativity in context. Affect and Creativity at Work, Westview (2005).

[3] H. Zhao - S.E. Seibert The Big Five personality dimensions and entrepreneurial status: $A$ meta-analytical review, Journal of Applied Psychology (2006).

[4] R.R. McCrae - O.P. John - An Introduction to the Five-Factor Model and Its Applications, Journal of Personality (1992)

[5] P. Costa Jr - R.R. McCrae Revised NEO Personality Inventory (NEO-PI-R) and NEO Five Factor Inventory (NEO-FFI) professional manual, Odessa (1992).

[6] F. Patterson Great minds don't think alike? Person-level predictors of innovation at work, International Review of Industrial and Organizational Psychology (2002).

[7] M.K. Mount - M.R. Barrick - G.L. Stewart Five-factor model of personality and performance in jobs involving interpersonal interactions, Human Performance (1998).

[8] R.R. McCrae Creativity, divergent thinking, and openness to experience, Journal of Personality and Social Psychology (1987).

[9] L.A. King - L.M. Walker - S.J. Broyles Creativity and the five-factor model, Journal of Research in Personality (1996).

[10] M.K. Barrick - M.R. Mount The Big Five personality dimensions and job performance: A meta-analysis, Personnel Psychology (1991).

[11] M.K. Mount - M.R Barrick - G.L. Stewart Five-factor model of personality and performance in jobs involving interpersonal interactions, Human Performance (1998).

[12] J. Zhou - J.M. George When job dissatisfaction leads to creativity: Encouraging the expression of voice, Academy of Management Journal (2001).

[13] A. Vance Elon Musk: Tesla, SpaceX, and the Quest for a Fantastic Future, Ecco (2015).

[14] D. Tweney, What's next from Elon Musk? Warp drives, and colonizing Mars, https: // venturebeat.com/2013/05/29/elon-musk-dreams-big/(2013).

[15] S. Outing, Zip2 Plays Up National Network Card, http: / / www . editorandpublisher .com/columns/zip2-plays-up-national-network-card/(1997).

[16] B.L. Ritholtz Elon Musk TED 2017, http://ritholtz.com/2017/05/elon-musk -ted-2017 (2017)

[17] Tech giants pledge $\$ 1$ bn for 'altruistic $A I^{\prime}$ venture, OpenAI, http://www.bbc.com/ news/technology-35082344 (2015).

[18] J. Reingold Hondas in Space,

https://www. fastcompany.com/52065/hondas-space (2005).

[19] TED Interview by C. Anderson Elon Musk: The mind behind Tesla, SpaceX, SolarCity, https://www.ted.com/talks/elon_musk_the_mind_behind_tesla_spacex_solarcity (2013).

[20] Forbes Interview by H. Elliott Driving with Elon Musk, https : / / www • youtube . com/ watch? v=R8PEnK3aoFQ (2012).

[21] A. Matus Elon Musk - The Big 5 Model, http://albertomatus.com/elon-musk -the-big-5-model (2016).

[22] R. Wartzman Admire Elon Musk all you want, but please don't manage like him, http: / / fortune.com/2015/01/21/elon-musk-micromanagement-control (2015).

[23] Business Insider Interview by K. Angelova Elon Musk Tells Us How He Went From 'An Introverted Engineer' To Being The New Steve Jobs http: / / www . businessinsider.com/ tesla-elon-musk-being-new-steve-jobs-2013-11? IR=T (2013).

[24] Inc. Magazine interview by S. Jurvetson Elon Musk: 5 Areas That Will Have the Most Important Effect on Humanity https : / / www . youtube. com/watch?v=h4vs jP_sKTo (2014). 